\title{
Genome size of 15 Lamiaceae taxa in Korea
}

\author{
Yoonkyung Lee and Sangtae Kim* \\ Department of Biology, Sungshin Women's University, Seoul 01133, Korea \\ (Received 22 May 2017; Revised 19 June 2017; Accepted 23 June 2017)

\section{한국산 꿀풀과 15 분류군에 대한 유전체양 조사} \\ 이윤경 · 김상태* \\ 성신여자대학교 생물학과
}

\begin{abstract}
The genome size is one of the basic characters of an organism, and it is widely applied in various fields of biology, such as systematics, breeding biology, population biology, and evolutionary biology. This factor was recently highlighted in genome studies because choosing a representative of a plant group having the smallest genome size is important for the efficiency of a genome project. For the estimation of the genome size, flow cytometry has recently been highlighted because it is a convenient, fast, and reliable method. In this study, we report the genome sizes of 15 taxa of Lamiaceae from nine genera distributed in Korea using flow cytometry. Data pertaining to the genome size for all of our species have not been reported thus far, and the data from Agastache, Clinopodium, Elsholtzia, and Isodon are the first reported for each genus. The genome sizes of 15 genera and 39 species were reported to the Plant DNA C-values Database (http:// data.kew.org/cvalues/). Scutellaria indica $\mathrm{L}$. has a genome size of $0.37 \mathrm{pg}(1 \mathrm{C})$. This is the fourth smallest value among the 98 Lamiaceae taxa in the Angiosperm DNA C-value Database, indicating that this taxon can be used as a reference species in the genome studies in Lamiaceae as a native Korean species. The largest genome size observed in this study is in Phlomis umbrosa Turcz. $(1 \mathrm{C}=2.60 \mathrm{pg})$, representing the possible polyploidy origin of this species in the family.
\end{abstract}

Keywords: genome size, DNA contents, C-value, flow cytometry, Lamiaceae

적 요: 한 생물체의 전체 유전체 크기는 계통학, 육종학, 집단유전학, 진화학과 같은 많은 분야에 활용될 수 있는 기본적인 정보이다. 최근에는 전체 유전체 결정 연구에서 특히 강조되고 있는데, 이는 최소 유전체 크기 를 갖는 분류군의 선택은 유전체 결정사업의 효율성과 직접적으로 연관되어 있기 때문이다. 그러므로 유전체 연구의 선행 단계로서 연구 대상 종 및 연관된 분류군들의 유전체 양의 파악은 필수적이다. 본 연구에서는 쉽 고 빠르면서도 신뢰성 있는 방법으로 알려져 있는 flow cytometry를 이용하여 한반도에 자생하는 꿀풀과의 9 속 15 분류군에 대한 유전체 크기를 측정하였다. 본 연구에서 유전체 양이 측정된 15 분류군들은 모두 최초로 그 유전체 양이 조사된 분류군들로서 Plant DNA C-value Database (http://data.kew.org/cvalues/)에 수록된 바 없 는데, 특히 Agastache, Clinopodium, Elsholtzia, Isodon에 속하는 분류군들은 속 수준에서의 최초의 보고이다. 골 무꽃(Scutellaria indica L.)은 $0.37 \mathrm{pg}(1 \mathrm{C})$ 의 유전체 크기를 갖는 것으로 측정되었는데, 이는 현재까지 보고된 꿀풀과 98 분류군의 유전체 양들 중 네 번째로 유전체의 크기가 작은 분류군이다. 이에 골무꽃은 향후 유전체 연구를 위해 꿀풀과를 대표할 한국 자생종으로서 우선적으로 선택하여 분석할 수 있는 종일 것이다. 조사된 분류군들 중 가장 유전체 크기가 큰 분류군은 속단(Phlomis umbrosa Turcz.; $1 \mathrm{C}=2.6 \mathrm{pg}$ )으로서 이는 다배체 형 성에 의한 본 종의 기원 가능성을 제시하고 있다.

주요어: 유전체 크기, DNA 양, C-값, 플로싸이토메트리, 꿀풀과

*Author for correspondence: amborella@sungshin.ac.kr 
진핵생물에 있어서 유전체의 양은 복제되지 않은 상태 의 반수체 염색체 보체(unreplicated haploid chromosome complement)에 포함되어 있는 $\mathrm{DNA}$ 양인 $1 \mathrm{C}$ 값(1C-value) 으로 나타낸다. 다양한 생물군에 있어서 유전체 양은 각 각의 분류군에 대한 특성으로 알려져 있고(Zonneveld et al., 2005), 이에 대한 정보는 분류학적, 진화학적 연구뿐 아니 라 세포학적, 발생학적, 생태학적, 분자생물학적 연구 등 다양한 생물연구 분야에 널리 활용되고 있다(Bennett et al., 2000; Bennett and Leitch, 2005, 2010; Leitch and Bennett, 2007). 피자식물에서는 $6.4 \mathrm{Mbp}(1 \mathrm{C}=0.065 \mathrm{pg})$ 의 작은 유전 체를 갖는 식물에서(Genlisea margaretae, Lentibulariaceae) (Greilhuber et al., 2006) $148.9 \mathrm{Gbp}(1 \mathrm{C}=152.23 \mathrm{pg})$ 의 매우 큰 유전체를 갖는 식물에 이르기 까지(Paris japonica, Melanthiaceae) (Pellicer et al., 2010) 2,000배 이상의 큰 변이 폭의 유전체 양이 보고된 바 있다. 그러나 유전체 양(C 값) 과 생물체의 복잡성과는 서로 상관관계가 없는 것이 보고 된 바 있고(Mirsky and Ris, 1951), 이러한 관계는 'C-value paradox'로 널리 알려져 있다(Thomas, 1971).

최근에는 유전체 양 측정에 대한 중요성이 전체 유전체 결정 연구에서 특히 강조되고 있는데, 이는 최소 유전체 크기를 갖는 분류군의 선택이 유전체 결정사업의 효율성 과 직접적으로 연관되어 있기 때문이다. 예를 들어, 고추 (Capsicum annum L.)의 유전체의 크기는 약 $3.48 \mathrm{Gbp}$ 로서 이를 결정하기 위해 $650.2 \mathrm{Gbp}$ (약 187×)의 염기서열을 생 산하여 결정한 바 있고(Kim et al., 2014), 약 $870 \mathrm{Mbp}$ 의 암 보렐라(Amborella trichophoda Baill.) 유전체 결정을 위해서 $23 \mathrm{Gbp}$ (약 $30 \times$ )의 염기서열을 생산해 낸 바 있다 (Amborella Genome Project, 2013). 최소 유전체 양을 갖는 분류군의 선택은 동일한 플랫폼의 차세대염기서열 결정 (NGS; Next Generation Sequencing)방법을 사용했을 때 얻 을 수 있는 데이터양을 증가시키고, 이를 정렬할 때 필요 한 컴퓨터 메모리를 최소화할 수 있다. 이에 유전체 연구 의 선행 단계로서 연구 대상 종 및 연관된 분류군들의 유 전체 양 파악은 필수적인 사항으로 인식 되고 있다 (Amborella Genome Project, 2013; Kim et al., 2014).

Plant DNA C-value Database (http://data.kew.org/cvalues/) 에는 현재까지 8,510 분류군의 식물에 대한 유전체 양이 보고되어 있고(release 6.0, Dec. 2012), 이들 중 피자식물은 7,541 분류군이 포함되어 있다(Angiosperm DNA C-value Database, release 8.0, Dec. 2012) (Bennett and Leitch, 2012). 식 물체 유전체 양 측정을 위해서 초기에는 많은 노력이 드는 화학적 추출법이 이용되었으나, Feulgen microdensitometry 나 flow cytometry 방법의 개발로 유전체 양 데이터의 축적 이 가속화 되어가고 있다(Bai et al., 2012). 특히 1983년 이 후에는 피자식물 분야에 쉽고 빠르면서도 정확한 방법인 flow cytometry가 도입되어 유전체 양 측정을 위한 기본적 인 방법으로써 정착되었다(Galbraith et al., 1983). 현재 flow cytometry 방법의 도입은 Angiosperm DNA C-value
Database의 피자식물 유전체 양 데이터의 축적을 가속화 시키고 있다.

꿀풀과(Lamiaceae) 식물은 분자계통학적 자료를 바탕으 로 한 피자식물의 최신 분류체계인 $\mathrm{APG} \mathrm{IV} \mathrm{분류체계}$ (Angiosperm Phylogeny Group, 2016)에서 진정쌍자엽류 (eudicots), 핵심진정쌍자엽류(core-eudicots), 국화류(asterids), 진정국화류 I (euasterids I), 꿀풀목(Lamiales)에 속하고 있 다. 이 과에는 전 세계적으로 약 236속 7,200종이 포함되어 있는데(Stevens, 2001), 많은 경제작물들이 포함되어 있고, 특히 Mentha (mint), Lavandula (lavender), Ocimum (basil), Rosmarinus (Rosmari)와 같은 식물들은 정유의 원료, 향신 료, 차와 같은 용도로 널리 이용되고 있다. 전체 한반도에 자생하는 식물이 정리된 바 있는 『The Genera of Vascular Plants of Korea』에서는 26속 65종의 꿀풀과 식물이 한반 도에 자생하고 있는 것으로 보고되어 있다(Suh et al., 2007). 하지만 최근 발표된 APG IV 시스템 (Angiosperm Phylogeny Group, 2016)에서는 꿀풀과는 Callicarpa, Caryopteris, Clerodendrum, Vitex와 같은 기존의 마편초과 의 일부 분류군을 포함하고 있다. 『The Genera of Vascular Plants of Korea』의 자료를 APG 시스템이 인식한 꿀풀과 의 범위에 따라 정리하면 한반도에 자생하는 꿀풀과 식물 에는 30속 73종이 포함된다.

Angiosperm DNA C-value Database (Bennett and Leitch, 2012)에는 현재까지 27속 83분류군 꿀풀과 식물들이 등록 되어 있는데, 이들 중 한반도 자생종들의 유전체 양은 아 직 보고된 바 없다. 이에 본 연구에서는 한반도에 자생하 는 꿀풀과 식물들 중 9속 15 분류군에 대하여 flow cytometry 방법에 의해 유전체 양을 측정하여 보고하고, 이 를 Angiosperm DNA C-value Database의 꿀풀과 식물들에 대한 자료와 비교하였다.

\section{재료 및 방법}

연구에 포함된 종들은 한반도에 자생하는 꿀풀과의 15 분류군들로서, 각각의 식물들은 자생지에서 채집된 후 성 신여자대학교 식물 포장에서 이식 재배하였고, 이들 생체 로부터 잎을 채취하여 flow cytometry에 의한 유전체 양 측 정에 사용하였다. 연구에 사용된 식물체들은 확증표본을 만들어 성신여자대학교 식물표본관에 보관하였다(Table 1).

Flow cytometry에서는 유전체 양을 이미 알고 있는 표준 시료들과 측정대상 분류군의 시료에 포함된 핵 속의 DNA 를 형광염료로 염색하여 측정된 형광량의 상대적인 값으 로 대상식물의 유전체 양을 측정하였다. 이를 위하여 사 용할 표준시료들은 Doležel et al. (2007)에 의해 제시된 바 있는데, 이들 중 Solanum lycopersicum L. 'Stupicke polni rane' $(2 \mathrm{C}=1.96 \mathrm{pg})$, Glycine max Merr. 'Polanka' $(2 \mathrm{C}=2.50$ $\mathrm{pg})$, Pisum sativum L. 'Ctirad' $(2 \mathrm{C}=9.09 \mathrm{pg})$ 의 종자를 
Table 1. Genome size of Korean Lamiaceae included in this study and their voucher information.

\begin{tabular}{|c|c|c|c|c|c|}
\hline Taxa & Korean name & Voucher information & $\begin{array}{l}\text { Standard } \\
\text { plant }^{\mathrm{a}}\end{array}$ & $1 \mathrm{C} \pm \mathrm{SD}^{\mathrm{b}}(\mathrm{pg})$ & $\begin{array}{l}\text { Genome } \\
\text { size (Gbp) }\end{array}$ \\
\hline Agastache rugosa (Fisch. \& Mey.) Kuntze & 배초향 & $\begin{array}{l}\text { S. Kim } 2010256 \\
\text { (SWU0009992) }\end{array}$ & $\mathrm{S}$ & $0.53 \pm 0.00$ & 0.52 \\
\hline Clinopodium chinense var. parviflorum (Kudô) Hara & 층층이꽃 & $\begin{array}{l}\text { S. Kim } 2010258 \\
\text { (SWU0009994) }\end{array}$ & $\mathrm{S}$ & $0.55 \pm 0.07$ & 0.54 \\
\hline Clinopodium gracile (Benth.) Matsum. & 애기탑꽃 & $\begin{array}{l}\text { S. Kim } 2011302 \\
\text { (SWU0000638) }\end{array}$ & $\mathrm{S}$ & $0.47 \pm 0.03$ & 0.46 \\
\hline Elsholtzia ciliata (Thunb.) Hyl. & 향유 & $\begin{array}{l}\text { S. Kim } 2011288 \\
\text { (SWU0000624) }\end{array}$ & $\mathrm{S}$ & $0.57 \pm 0.01$ & 0.55 \\
\hline Isodon inflexus (Thunb.) Kudo & 산박하 & $\begin{array}{l}\text { S. Kim } s . n . \\
\text { (SWU0004814) }\end{array}$ & S & $0.51 \pm 0.03$ & 0.5 \\
\hline Leonurus japonicus Houtt. & 익모초 & $\begin{array}{l}\text { S. Kim } s . n . \\
\text { (SWU0004816) }\end{array}$ & $\mathrm{S}$ & $0.61 \pm 0.00$ & 0.6 \\
\hline Phlomis umbrosa Turcz. & 속단 & $\begin{array}{l}\text { S. Kim } 2010265 \\
\text { (SWU0010001) }\end{array}$ & $\mathrm{P}$ & $2.60 \pm 0.03$ & 2.54 \\
\hline Prunella vulgaris subsp. asiatica (Nakai) H. Hara & 꿀풀 & $\begin{array}{l}\text { S. Kim } 2010248 \\
\text { (SWU0009984) }\end{array}$ & G & $0.74 \pm 0.02$ & 0.72 \\
\hline Scutellaria indica $\mathrm{L}$. & 골무꽃 & $\begin{array}{l}\text { S. Kim 2015-0111 } \\
\text { (SWU0010036) }\end{array}$ & $\mathrm{S}$ & $0.37 \pm 0.01$ & 0.36 \\
\hline Scutellaria indica var. coccinea S. Kim \& S. T. Lee & 연지골무꽃 & $\begin{array}{l}\text { S. Kim 2015-0298 } \\
\text { (SWU0010338) }\end{array}$ & $\mathrm{S}$ & $0.39 \pm 0.02$ & 0.38 \\
\hline Scutellaria insignis Nakai & 광릉골무꽃 & $\begin{array}{l}\text { S. Kim 2015-0110 } \\
\text { (SWU0010035) }\end{array}$ & $\mathrm{S}$ & $0.47 \pm 0.01$ & 0.46 \\
\hline Scutellaria pekinensis var. maxima S. Kim \& S. T. Lee & 왕골무꽃 & $\begin{array}{l}\text { S. Kim 2015-0108 } \\
\text { (SWU0010033) }\end{array}$ & S & $0.46 \pm 0.01$ & 0.45 \\
\hline $\begin{array}{l}\text { Scutellaria pekinensis var. transitra (Makino) H. Hara } \\
\text { ex H. W. Li }\end{array}$ & 산골무꽃 & $\begin{array}{l}\text { S. Kim 2015-0109 } \\
\text { (SWU0010034) }\end{array}$ & $\mathrm{S}$ & $0.47 \pm 0.00$ & 0.46 \\
\hline Scutellaria strigillosa Hemsl. & 참골무꽃 & $\begin{array}{l}\text { S. Kim } 20140705 \\
\text { (SWU0006319) }\end{array}$ & $\mathrm{S}$ & $0.39 \pm 0.01$ & 0.38 \\
\hline Thymus quinquecistatus var. japonicus H. Hara & 섬백리향 & $\begin{array}{l}\text { S. Kim 2015-0296 } \\
\text { (SWU0010336) }\end{array}$ & $\mathrm{S}$ & $0.52 \pm 0.00$ & 0.51 \\
\hline
\end{tabular}

a', Solanum lycopersicum L. 'Stupicke polni rane' $(2 \mathrm{C}=1.96$ pg); P, Pisum sativum L. 'Ctirad' (2C = 9.09 pg); G, Glycine max Merr. 'Polanka' ( $2 \mathrm{C}=2.50 \mathrm{pg}) .{ }^{\mathrm{b}} 1 \mathrm{C}$ nuclear DNA contents (mean \pm standard deviation).

Doležel (Institute of Experimental Botany AS CR; http:// www.ueb.cas.cz/en)로부터 제공받아 성신여자대학교 온실 에 파종 재배한 후, 이들의 잎을 유전체 양 측정을 위한 표 준시료로 사용하였다.

유전체 양 측정에서 표준시료와 측정하고자 하는 시료 의 $1 \mathrm{C}$ 값이 2.5 배 이내가 되는 표준시료의 사용을 제시하 고 있다(Doležel et al., 2007). 이 충족시키기 위해서 Plant DNA C-values Database (http://data.kew.org/cvalues/)에 이 미 보고되어 있는 꿀풀과 분류군들의 유전체 양 정보를 이용하여 실험 대상 분류군의 유전체 양을 예측하였고, 이를 바탕으로 표준시료를 선정하였다. 이후 선택된 표 준시료를 이용하여 대상시료의 유전체 양을 측정하였고, 그 결과 이들 간의 유전체 양의 차이가 2.5 배 이하인 결과
만을 사용하였고, 2.5 배 이상인 시료에 대해서는 크기가 다른 유전체 양을 갖는 표준시료로서 실험을 반복하였다 (Table 1). 유전체 양의 측정은 Doležel et al. (2007)의 방법 을 따라 잎 조직 세포의 핵을 형광 염색하여 $2 \mathrm{C}$ 값을 측정 하였다. 각각의 생체시료와 표준 시료로부터 약 $5 \mathrm{~mm}^{2}$ 의 잎을 채취하여 $4^{\circ} \mathrm{C}$ 의 DAPI Prep DNA Staining Solution (SONY Biotechnology Inc., San Jose, CA, USA) 하에서 조 직을 면도날로 잘게 잘라 약 2 분간 용해 및 염색시켰다. 염색된 세포의 형광도의 측정은 Cell Sorter SH800 (SONY Biotechnology Inc., San Jose, CA, USA)를 이용하였는데, 각각의 측정은 5,000 event 이상을 포함하였고, 다른 잎 또 는 다른 개체를 이용하여 3 회 이상 반복 측정하여 평균과 표준편차를 구했다. $1 \mathrm{C}$ 값은 표준 시료의 세포분열 단계 

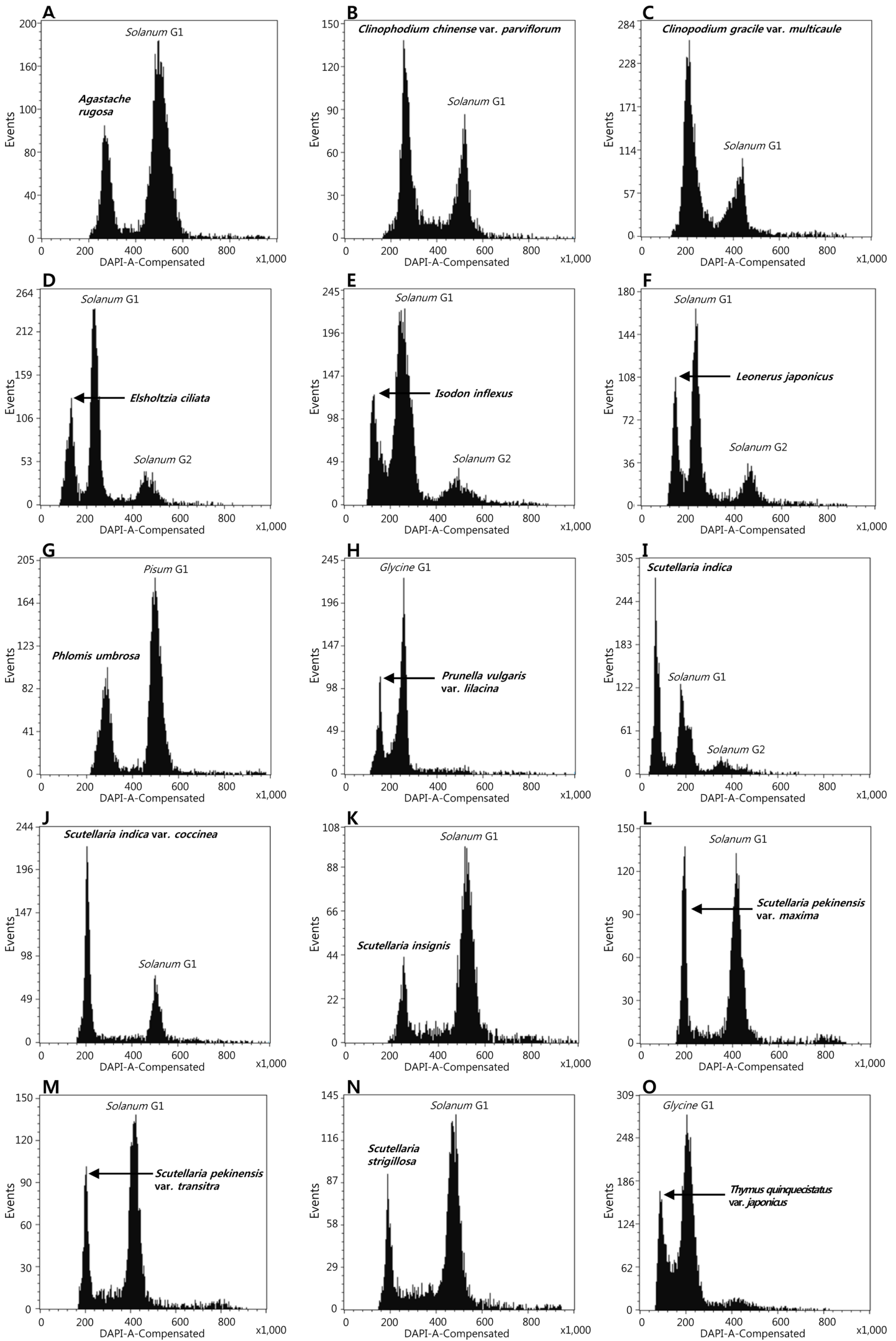

Fig. 1. Flow cytometry histograms showing picks of size-standard plants and targeted samples (bold). More than 5,000 count events are included in each estimation. 
상의 G1 (growth 1) stage의 peak 위치를 기준으로 실험 대 상 시료들의 상대적인 peak 위치 값으로 $2 \mathrm{C}$ 값을 구하여 도출하였으며, 최종적으로 “ $1 \mathrm{C}(\mathrm{pg}) \mathrm{DNA}=0.978 \times 10^{9} \mathrm{bp}$ (Doležel et al., 2003)"의 식에 대입하여 염기수에 의한 유 전체의 크기를 계산하였다.

\section{결과 및 고찰}

\section{한반도 고유종 꿀풀과 식물들의 유전체 양}

본 연구에서는 한반도에 자생하는 꿀풀과 식물 9 속 15 분류군에 대한 유전체 양을 측정하였는데, 이들은 $0.37-$ $2.60 \mathrm{pg}$ (1C)의 유전체 양을 갖고 있었다(Fig. 1, Table 1). 조 사된 식물들 중 가장 작은 유전체를 갖는 분류군은 골무 꽃(Scutellaria indica $\mathrm{L}$.)으로 $0.37 \mathrm{pg}$ 의 $1 \mathrm{C}$ 값을 갖는다(Fig. 1, Table 1). 현재까지 Angiosperm DNA C-value Database에 유전체 양이 보고된 꿀풀과 식물은 83 분류군인데(Bennett and Leitch, 2012), 본 연구를 통해 제공된 15 분류군을 합친 전체 98 분류군들(Table 2) 중 골무꽃은 Nepeta teydea Webb \& Berthel. ( $1 \mathrm{C}=0.28 \mathrm{pg})$, Mentha $\mathrm{x}$ piperita $\mathrm{L} .(1 \mathrm{C}=0.33$ $\mathrm{pg})$, Micromeria hyssopifolia Webb \& Berthel. $(1 \mathrm{C}=0.36 \mathrm{pg})$ 에 이어 네 번째로 작은 유전체를 갖는다. 골무꽃보다 작 은 유전체를 갖는 이들 세 종은 모두 한반도에 자생하는 식물이 아니며, 따라서 골무꽃은 향후 한반도 자생 꿀풀 과 종들에 대한 유전체 연구를 위해 우선적으로 선택해야
할 후보 식물이 될 수 있을 것이다.

본 연구에 포함된 분류군들 중 배초향[Agastache rugosa (Fisch. \& Mey.) Kuntze]은 $0.53 \mathrm{pg}$, 층층이꽃 [Clinopodium chinense var. parviflorum (Kudô) Hara]은 0.55 pg, 애기탑꽃 [Clinopodium gracile (Benth.) Matsum.]은 $0.47 \mathrm{pg}$, 산박하 [Isodon inflexus (Thunb.) Kudo]는 $0.51 \mathrm{pg}$ 의 $1 \mathrm{C}$ 값을 갖는데, 이들은 Agastache, Clinopodium, Isodon에 대한 최초의 보고 이다. 한반도의 특산 식물인 광릉골무꽃(Scutellaria insignis Nakai)과 섬백리향(Thymus quinquecistatus var. japonicus $\mathrm{H}$. Hara)은 각각 $0.47 \mathrm{pg}(1 \mathrm{C}), 0.52 \mathrm{pg}$ (1C) 값을 갖고 있었다 (Fig. 1, Table 1).

본 연구에 의해 측정된 한반도에 자생하는 꿀풀과 식물 들 중 가장 큰 유전체 양을 갖는 분류군은 속단(Phlomis umbrosa Turcz.; $1 \mathrm{C}=2.60 \mathrm{pg}$ )이다(Fig. 1, Table 1). Phlomis 내에서는 현재까지 P. tuberosa의 유전체 크기만이 보고되 어 있는데 $(1 \mathrm{C}=2.02 \mathrm{pg})$, 본 연구에서 포함된 국내 분포 종 인 속단(P. umbrosa)은 이와 비슷한 유전체 크기를 갖고 있 었다 $(1 \mathrm{C}=2.6 \mathrm{pg})$. 본 연구를 포함하여 현재까지 보고된 꿀풀과 식물 98 분류군들 중에서 각 속의 최소 유전체 양 을 갖는 분류군들의 평균값은 0.93 (1C)이고(Table 2), P. tuberosa와 속단은 이보다 두 배 이상의 유전체 크기를 갖 고 있다. 속단의 염색체 수는 지금까지 보고된 바 없는데, 유전체 크기 측정 자료는 속단의 다배체 형성에 의한 기 원 가능성을 제시하고 있다.

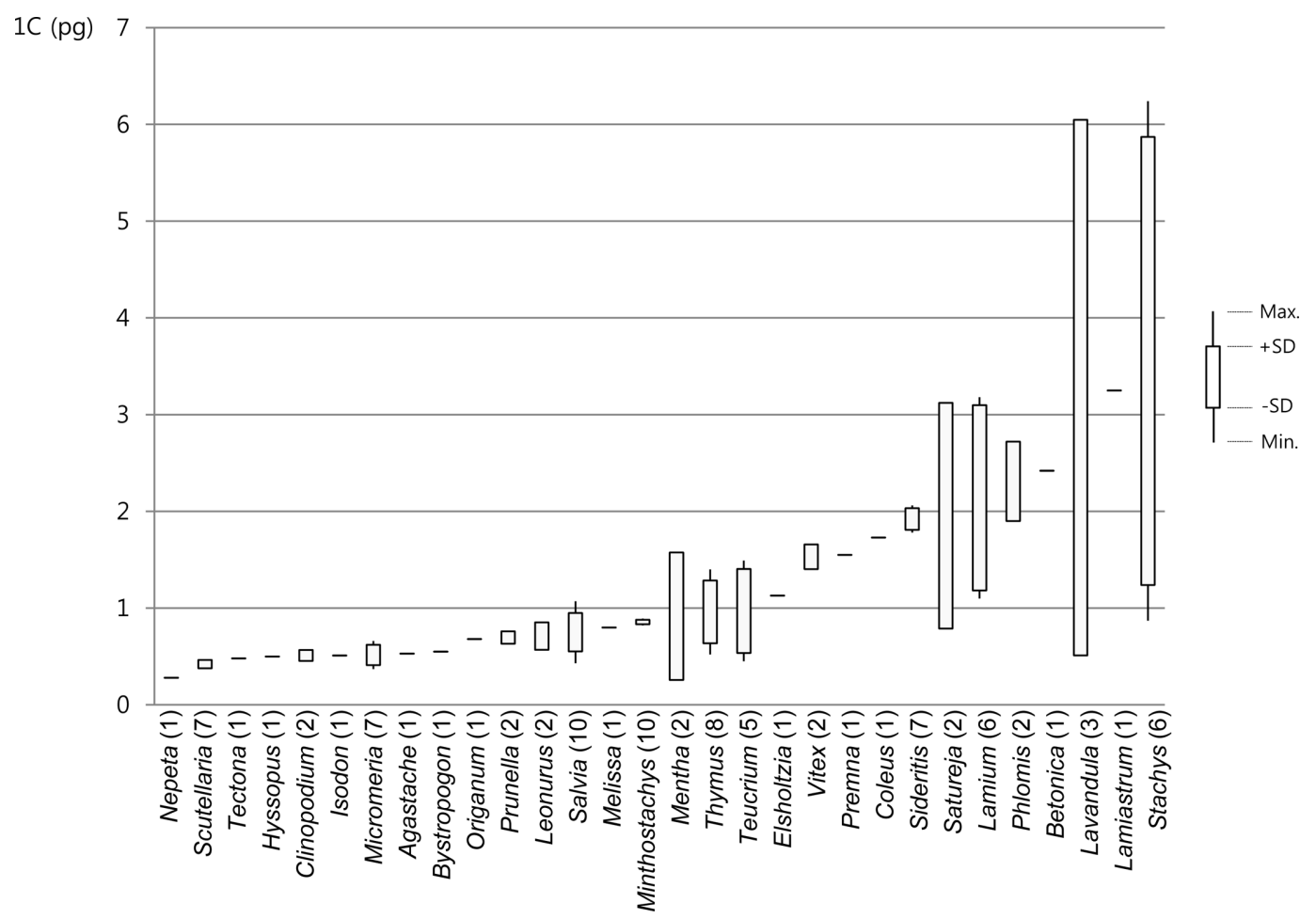

Fig. 2. Range of genome size (1C value) in each genus of Lamiaceae. Taxon order is rearranged by the amount of mean value of genome size in each genus. Numbers after the genus name indicate number of taxa included in the genus. 


\section{꿀풀과 식물의 유전체 양에 대한 고찰}

속 내 여러 분류군들에 대한 유전체 양 정보가 축적되면 속내 종들의 기본염색체 $(x)$ 에 대한 유전체 양의 추정이 가 능하다. 본 연구에서 새로이 보고된 15 분류군들의 유전 체 양 데이터를 포함하여 전체 꿀풀과 식물들에 대한 유 전체 양 데이터를 종합한 결과(Fig. 2, Table 2), Lamium, Lavandula, Mentha, Salvia, Satureja, Stachys, Teucrium, Thymus의 8속에서는 속 내 분류군들의 최대 유전체 양과 최소 유전체 양이 두 배 이상 차이 나는데, 이는 속 내에서 다배체 현상에 의한 종 분화가 일어 났음을 제시하고 있 고, IPCN (Index to Plant Chromosome Number; http:// www.tropicos.org/Project/IPCN)에 지금까지 보고된 염색체 자료에서도 이를 확인할 수 있다. 특히 Stachys 내에서는
최소 유전체 양을 가지는 Stachys recta L. $(1 \mathrm{C}=0.87)$ 와 최 대 유전체 양을 가지는 Stachys grandiflora Host $(1 \mathrm{C}=6.24)$ 가 7배 정도의 차이를 보였다.

본 연구에서 이루어진 한국산 꿀풀과 식물들의 유전체 양 조사는 현재까지 한반도에 보고된 꿀풀과 식물들 30 속 73 종(APG 시스템에서의 확장된 과의 영역 포함; Suh et al., 2007) 중 속 수준에서 $30.0 \%$, 종 수준으로는 $19.2 \%$ 의 분 류군에 해당한다. 또한 본 연구는 전세계적으로 축적된 꿀풀과 식물에 대한 유전체 양 데이터를 $18 \%$ 증가시키고 있다. 향후 꿀풀과 식물들에 대하여 보다 많은 유전체양 자료의 축적은 염색체 수 자료와 함께 꿀풀과 식물들의 진화와 다양화 과정에 대한 이해를 위한 기초자료로 중요 한 역할을 할 것으로 생각된다.

Table 2. Genome size of Lamiaceae reported to date including this study.

\begin{tabular}{|c|c|c|}
\hline Taxon & $1 \mathrm{C}(\mathrm{pg})$ & Reference \\
\hline Agastache rugosa (Fisch. \& C. A .Mey.) Kuntze & 0.53 & This study \\
\hline Betonica alopecuros $\mathrm{L}$. & 2.42 & Temsch et al., 2010 \\
\hline Bystropogon canariensis (L.) L'Hér. & 0.55 & Suda et al., 2005 \\
\hline Clinopodium chinense var. parviflorum (Kudô) H.Hara & 0.55 & This study \\
\hline Clinopodium gracile var. multicaule (Maxim.) Ohwi & 0.47 & This study \\
\hline Coleus blumei Benth. & 1.73 & Galbraith et al., 1983 \\
\hline Elsholtzia ciliata (Thunb.) Hyl. & 1.13 & This study \\
\hline Hyssopus officinalis $\mathrm{L}$. & 0.5 & Olszewska and Osiecka, 1983 \\
\hline Isodon inflexus (Thunb.) Kudô & 0.51 & This study \\
\hline Lamiastrum galeobdolon (L.) Ehrend. \& Polatschek & 3.25 & Band, $1984^{\mathrm{a}}$ \\
\hline Lamium album $\mathrm{L}$. & 1.1 & Bennett, 1972 \\
\hline Lamium argentatum (Smejkal) Henker ex G. H. Loos & 3.17 & Rosenbaumová et al., 2004 \\
\hline Lamium flavidum F. Herm. & 1.71 & Rosenbaumová et al., 2004 \\
\hline Lamium galeobdolon (L.) L. & 1.64 & Rosenbaumová et al., 2004 \\
\hline Lamium montanum (Pers.) Hoffm. ex Kabath & 3.18 & Rosenbaumová et al., 2004 \\
\hline Lamium purpureum $\mathrm{L}$. & 1.1 & Bennett, 1972 \\
\hline Lavandula buchii Webb \& Berthel. & 0.51 & Suda et al., 2003 \\
\hline Lavandula multifida $\mathrm{L}$. & 0.51 & Suda et al., 2003 \\
\hline Lavandula officinalis Chaix & 5.65 & Zonneveld et al., 2005 \\
\hline Leonurus cardiac L. & 0.81 & Bainard et al., 2011 \\
\hline Leonurus japonicus Houtt. & 0.61 & This study \\
\hline Melissa officinalis L. & 0.8 & Olszewska and Osiecka, 1983 \\
\hline Melittis melissophyllum $\mathrm{L}$. & 0.48 & Siljak-Yakovlev et al., 2010 \\
\hline Mentha aquatica $\mathrm{L}$. & 1.5 & Band, $1984^{\mathrm{a}}$ \\
\hline Mentha longifolia (L.) L. & 0.39 & Hanson et al., 2002 \\
\hline Mentha $\mathrm{x}$ piperita $\mathrm{L}$. & 0.33 & Olszewska and Osiecka, 1983 \\
\hline Micromeria glomerata P. Pérez & 0.44 & Suda et al., 2003 \\
\hline Micromeria herpyllomorpha Webb \& Berthel. & 0.38 & Suda et al., 2003 \\
\hline Micromeria hyssopifolia Webb \& Berthel. & 0.36 & Suda et al., 2003 \\
\hline Micromeria lachnophylla Webb \& Berthel. & 0.37 & Suda et al., 2003 \\
\hline Micromeria pseudocroatica Šilić & 0.66 & Siljak-Yakovlev et al., 2010 \\
\hline Micromeria thymifolia (Scop.) Fritsch & 0.44 & Siljak-Yakovlev et al., 2010 \\
\hline Micromeria varia Benth. & 0.38 & Suda et al., 2003 \\
\hline Minthostachys acris Schmidt-Leb. & 0.88 & Schmidt-Lebuhn et al., 2008 \\
\hline Minthostachys acutifolia Epling & 0.87 & Schmidt-Lebuhn et al., 2008 \\
\hline
\end{tabular}


Table 2. Continued.

\begin{tabular}{|c|c|c|}
\hline Taxon & $1 \mathrm{C}(\mathrm{pg})$ & Reference \\
\hline Minthostachys andina (Britton ex Rusby) Epling & 0.88 & Schmidt-Lebuhn et al., 2008 \\
\hline Minthostachys dimorpha Schmidt-Leb. & 0.87 & Schmidt-Lebuhn et al., 2008 \\
\hline Minthostachys latifolia Schmidt-Leb. & 0.83 & Schmidt-Lebuhn et al., 2008 \\
\hline Minthostachys mollis (Benth.) Griseb. & 0.84 & Schmidt-Lebuhn et al., 2008 \\
\hline Minthostachys ovate (Briq.) Epling & 0.89 & Schmidt-Lebuhn et al., 2008 \\
\hline Minthostachys rubra Schmidt-Leb. & 0.85 & Schmidt-Lebuhn et al., 2008 \\
\hline Minthostachys spicata (Benth.) Epling & 0.82 & Schmidt-Lebuhn et al., 2008 \\
\hline Minthostachys verticillata (Griseb.) Epling & 0.86 & Schmidt-Lebuhn et al., 2008 \\
\hline Nepeta teydea Webb \& Berthel. & 0.28 & Suda et al., 2003 \\
\hline Origanum vulgare $\mathrm{L}$. & 0.68 & Mowforth, 1985 \\
\hline Phlomis tuberosa $\mathrm{L}$. & 2.02 & Veselý et al., 2012 \\
\hline Phlomis umbrosa Turcz. & 2.6 & This study \\
\hline Premna latifolia Roxb. & 1.55 & Ohri et al., 2004 \\
\hline Prunella vulgaris $\mathrm{L}$. & 0.65 & Temsch et al., 2010 \\
\hline Prunella vulgaris var. asiatica (Nakai) H. Hara & 0.74 & This study \\
\hline Salvia brachyodon Vandas & 0.48 & Maksimović et al., 2007 \\
\hline Salvia broussonetii Benth. & 0.43 & Suda et al., 2003 \\
\hline Salvia canariensis L. & 0.5 & Suda et al., 2005 \\
\hline Salvia glutinosa $\mathrm{L}$. & 1.07 & Temsch et al., 2010 \\
\hline Salvia nemorosa $\mathrm{L}$. & 0.55 & Siljak-Yakovlev et al., 2010 \\
\hline Salvia officinalis L. & 0.49 & Maksimović et al., 2007 \\
\hline Salvia ringens $\mathrm{Sm}$. & 0.61 & Siljak-Yakovlev et al., 2010 \\
\hline Salvia sclarea $\mathrm{L}$. & 0.58 & Siljak-Yakovlev et al., 2010 \\
\hline Salvia splendens Sellow ex Schult. & 0.85 & Olszewska and Osiecka, 1983 \\
\hline Salvia verticillata $\mathrm{L}$. & 0.7 & Siljak-Yakovlev et al., 2010 \\
\hline Satureja cuneifolia Ten. & 1.13 & Siljak-Yakovlev et al., 2010 \\
\hline Satureja montana $\mathrm{L}$. & 2.78 & Ceccarelli et al., 1998 \\
\hline Scutellaria altissima $\mathrm{L}$. & 0.4 & Kubešová et al., 2010 \\
\hline Scutellaria indica $\mathrm{L}$. & 0.37 & This study \\
\hline Scutellaria indica var coccinea S. Kim \& S. T. Lee & 0.39 & This study \\
\hline Scutellaria insignis Nakai & 0.47 & This study \\
\hline Scutellaria pekinensis var. maxima S. Kim \& S. T. Lee & 0.46 & This study \\
\hline Scutellaria pekinensis var transitra (Makino) H. Hara & 0.47 & This study \\
\hline Scutellaria strigillosa Hemsl. & 0.39 & This study \\
\hline Sideritis brevicaulis Mend.-Heuer & 1.83 & Suda et al., 2005 \\
\hline Sideritis canariensis $\mathrm{L}$. & 1.78 & Suda et al., 2003 \\
\hline Sideritis cretica $\mathrm{L}$. & 2.06 & Suda et al., 2005 \\
\hline Sideritis dendro-chahorra Bolle & 1.82 & Suda et al., 2005 \\
\hline Sideritis infernalis Bolle & 1.81 & Suda et al., 2005 \\
\hline Sideritis macrostachys Poir. & 2.02 & Suda et al., 2003 \\
\hline Sideritis oroteneriffae Négrin \& P. Pérez & 1.83 & Suda et al., 2003 \\
\hline Stachys grandiflora Host & 6.24 & Barow and Meister, 2003 \\
\hline Stachys iva Griseb. & 0.94 & Siljak-Yakovlev et al., 2010 \\
\hline Stachys menthaefolia Vis. & 1.04 & Siljak-Yakovlev et al., 2010 \\
\hline Stachys officinalis (L.) Trevis. & 4.53 & Band, $1984^{\mathrm{a}}$ \\
\hline Stachys recta $\mathrm{L}$ & 0.87 & Siljak-Yakovlev et al., 2010 \\
\hline Stachys sylvatica $\mathrm{L}$. & 1.28 & Siljak-Yakovlev et al., 2010 \\
\hline Tectona grandis L.f. & 0.48 & Ohri and Kumar, 1986 \\
\hline Teucrium arduini $\mathrm{L}$. & 0.45 & Siljak-Yakovlev et al., 2010 \\
\hline Teucrium flavum $\mathrm{L}$. & 1.49 & Siljak-Yakovlev et al., 2010 \\
\hline
\end{tabular}


Table 2. Continued.

\begin{tabular}{lcc}
\hline \hline \multicolumn{1}{c}{ Taxon } & $1 \mathrm{C}(\mathrm{pg})$ & Reference \\
\hline Teucrium heterophyllum L'Hér. & 1.15 & Suda et al., 2005 \\
Teucrium montanum L. & 0.6 & Siljak-Yakovlev et al., 2010 \\
Teucrium scorodonia L. & 1.18 & Band, 1984 $^{\mathrm{a}}$ \\
Thymus acicularis Waldst. \& Kit. & 0.61 & Siljak-Yakovlev et al., 2010 \\
Thymus daënensis Celak. & 0.55 & Mahdavi and Karimzadeh, 2010 \\
Thymus daënensis Celak. & 1.21 & Mahdavi and Karimzadeh, 2010 \\
Thymus eriocalyx (Ronniger) Jalas & 0.64 & Mahdavi and Karimzadeh, 2010 \\
Thymus migricus Klokov \& Des.-Shost. & 0.71 & Mahdavi and Karimzadeh, 2010 \\
Thymus praecox Opiz & 1.4 & Mowforth, 1985 \\
Thymus quinquecistatus var. japonicus H. Hara & 0.52 & This study \\
Thymus vulgaris L. & 0.78 & Marie and Brown, 1993 \\
Vitex negundo L. & 1.62 & Ohri, 2002 $^{\mathrm{a}}$ \\
Vitex pinnata L. & 1.44 & Ohri, 2002 $^{\mathrm{a}}$ \\
\hline
\end{tabular}

${ }^{\mathrm{a}}$ Personal communication by M. D. Bennett and J. J. Leitch in the Plant DNA C-value Database.

\section{Acknowledgments}

This study was supported by National Institute of Biological Resources of Korea (NIBR 201513201).

\section{Literature Cited}

Amborella Genome Project. 2013. The Amborella genome and the evolution of flowering plants. Science 342: 1241089.

Angiosperm Phylogeny Group. 2016. An update of the angiosperm phylogeny group classification for the orders and families of flowering plants: APG IV. Botanical Journal of the Linnean Society 181: 1-20.

Bai, C., W. S. Alverson, A. Follansbee and D. M. Waller. 2012. New reports of nuclear DNA content for 407 vascular plant taxa from the United States. Annals of botany 110: 16231629.

Bainard, J. D., B. C. Husband, S. J. Baldwin, A. J. Fazekas, T. R. Gregory, S. G. Newmaster and P. Kron. 2011. The effects of rapid desiccation on estimates of plant genome size. Chromosome Research 19: 825-842.

Barow, M. and A. Meister. 2003. Endopolyploidy in seed plants is differently correlated to systematics, organ, life strategy and genome size. Plant Cell and Environment 26: 571-584.

Bennett, M. D. 1972. Nuclear DNA content and minimum generation time in herbaceous plants. Proceedings of the Royal Society of London Series B Biological Sciences 181: 109135.

Bennett, M. D., P. Bhandol and I. J. Leitch. 2000. Nuclear DNA amounts in angiosperms and their modern uses: 807 new estimates. Annals of Botany 86: 859-909.

Bennett, M. D. and I. J. Leitch. 2005. Plant DNA C-values Data- base (Release 4.0). Royal Botanic Gardens, Kew.

Bennett, M. D. and I. J. Leitch. 2010. Plant DNA C-values Database (Release 5.0). Royal Botanic Gardens, Kew.

Bennett, M. D. and I. J. Leitch. 2012. Angiosperm DNA C-values Database (Release 8.0). Royal Botanic Gardens, Kew.

Ceccarelli, M., L. Morosi and P. G. Cionini. 1998. Chromocenter association in plant cell nuclei: determinants, functional significance, and evolutionary implications. Genome 41: 96-103.

Doležel, J., J. Bartoš, H. Voglmayr and J. Greilhuber. 2003. Nuclear DNA content and genome size of trout and human. Cytometry A 51: 127-128.

Doležel, J., J. Greilhuber and J. Suda. 2007. Estimation of nuclear DNA content in plants using flow cytometry. Nature Protocols 2: 2233-2244.

Galbraith, D. W., K. R. Harkins, J. M. Maddox, N. M. Ayres, D. P. Sharma and E. Firoozabady. 1983. Rapid flow cytometric analysis of the cell cycle in intact plant tissues. Science 220: 1049-1051.

Greilhuber, J., T. Borsch, K. Müller, A. Worberg, S. Porembski and W. Barthlott. 2006. Smallest angiosperm genomes found in Lentibulariaceae, with chromosomes of bacterial size. Plant Biology 8: 770-777.

Hanson, L., I. J. Leitch and M. D. Bennett. 2002. Unpublished data from the Jodrell Laboratory, Royal Botanic Gardens, Kew.

Kim, S., M. Park, S.,-I., Yeom, Y.-M. Kim, J. M. Lee, H.-A. Lee, E. Seo, J. Choi, K. Cheong, K.-T. Kim, K. Jung, G.-W. Lee, S.K. Oh, C. Bae, S.-B. Kim, H.-Y. Lee, S.-Y. Kim, M.-S. Kim, B.-C. Kang, Y. D. Jo, H.-B. Yang, H.-J. Jeong, W.-H. Kang, J.K. Kwon, C. Shin, J. Y. Lim, J. H. Park, J. H. Huh, J.-S. Kim, B.-D. Kim, O. Cohen, I. Paran, M. C. Suh, S. B. Lee, Y.-K. Kim, Y. Shin, S.-J. Noh, J. Park, Y. S. Seo, S.-Y. Kwon, H. A 
Kim, J. M. Park, H.-J. Kim, S.-B. Choi, P. W. Bosland, G. Reeves, S.-H. Jo, B.-W. Lee, H.-T. Cho, H.-S. Choi, M.-S. Lee, Y. Yu, Y. D. Choi, B.-S. Park, A. van Deynze, H. Ashrafi, T. Hill, W. T. Kim, H.-S. Pai, H. K. Ahn, I. Yeam, J. J. Giovannoni, J. K. C. Rose, I. Sørensen, S.-J. Lee, R. W. Kim, I.-Y. Choi, B.-S. Choi, J.-S. Lim, Y.-H. Lee and D. Cho. 2014. Genome sequence of the hot pepper provides insights into the evolution of pungency in Capsicum species. Nature Genetics 46: 270-278.

Kubešová, M., L. Moravcova, J. Suda, V. Jarošík and P. Pyšek. 2010. Naturalized plants have smaller genomes than their noninvading relatives: a flow cytometric analysis of the Czech alien flora. Preslia 82: 81-96.

Leitch, I. J. and M. D. Bennett. 2007. Genome size and its uses: the impact of flow cytometry. In Flow Cytometry with Plant Cells: Analysis of Genes, Chromosones, and Genomes. Doležel, J., J. Greilhuber and J. Suda (eds.), Wiley-VCH, Weinheim. Pp. 153-176.

Mahdavi, S. and G. Karimzadeh. 2010. Karyological and nuclear DNA content variation in some Iranian endemic Thymus species (Lamiaceae). Journal of Agricultural Science and Technology 12: 447-458.

Maksimović, M., D. Vidic, M. Miloš, M. E. Šolić, S. Abadžić and S. Siljak-Yakovlev. 2007. Effect of the environmental conditions on essential oil profile in two Dinaric Salvia species: $S$. brachyodon Vandas and S. officinalis L. Biochemical Systematics and Ecology 35: 473-478.

Marie D. and S. C. Brown. 1993. A cytometric exercise in plant DNA histograms, with $2 \mathrm{C}$ values for 70 species. Biology of the Cell 78: 41-51.

Mirsky, A. E. and H. Ris. 1951. The desoxyribonucleic acid content of animal cells and its evolutionary significance. The Journal of General Physiology 34: 451-462.

Mowforth, M. A. 1985. Variation in nuclear DNA amounts in flowering plants: An ecological anlaysis (Doctoral dissertation). University of Sheffield, Sheffield.

Ohri, D. and A. Kumar. 1986. Nuclear DNA amounts in some tropical hardwoods. Caryologia 39: 303-307.

Ohri, D., A. Bhargava and A. Chatterjee. 2004. Nuclear DNA amounts in 112 species of tropical hardwoods: New estimates. Plant Biology 6: 555-561.

Olszewska, M. J. and R. Osiecka. 1983. The relationship between 2 C DNA content, life cycle type, systematic position and the dynamics of DNA endoreplication in parenchyma nuclei during growth and differentiation of roots in some dicotyledonous herbaceous species. Biochemie und Physiologie der Pflanzen 178: 581-599.

Pellicer, J., M. F. Fay and I. J. Leitch. 2010. The largest eukaryotic genome of them all? Botanical Journal of the Linnean Society 164: 10-15.

Rosenbaumová, R., I. Plačková and J. Suda. 2004. Variation in Lamium subg. Galeobdolon (Lamiaceae): Insights from ploidy levels, morphology and isozymes. Plant Systematics and Evolution 244: 219-244.

Schmidt-Lebuhn, A. N., J. Fuchs and M. Kessler. 2008. Flow cytometric measurements do not reveal different ploidy levels in Minthostachys (Lamiaceae). Plant Systematics and Evolution 271: 123-128.

Siljak-Yakovlev, S., F. Pustahija, E. M. Šolic, F. Bogunić, E. Muratović, N. Bašić, O. Catrice and S. C. Brown. 2010. Towards a genome size and chromosome number database of Balkan flora: C-values in 343 taxa with novel values for 242 . Advanced Science Letters 3: 190-213.

Stevens, P. F. 2001. Angiosperm Phylogeny Website (version 12). Retrieved Jul. 2012, available from http://www.mobot.org/ MOBOT/research/APweb/.

Suda, J., T. Kyncl and R. Freíová. 2003. Nuclear DNA amounts in Macaronesian angiosperms. Annals of Botany 92: 153-164.

Suda, J., T. Kyncl and V. Jarolímová. 2005. Genome size variation in Macaronesian angiosperms: Forty percent of the Canarian endemic flora completed. Plant Systematics and Evolution 252: 215-238.

Suh, Y., S. Hong and S. Park. 2007. Lamiaceae. In The Genera of Vascular Plants of Korea. Park, C.-W. (ed.). Academy Publ. Co., Seoul. Pp. 815-841. (in Korean)

Temsch, E. M., W. Temsch, L. Ehrendorfer-Schratt and J. Greilhuber. 2010. Heavy metal pollution, selection, and genome size: The species of the Žerjav study revisited with flow cytometry. Journal of Botany 2010: 596542.

Thomas C. A. Jr. 1971. The genetic organization of chromosomes. Annual Review of Genetics 5: 237-256.

Veselý, P., P. Bureš, P. Šmarda and T. Pavlíček. 2012. Genome size and DNA base composition of geophytes: The mirror of phenology and ecology? Annals of Botany 109: 65-75.

Zonneveld, B. J. M., I. J. Leitch and M. D. Bennett. 2005. First nuclear DNA amounts in more than 300 angiosperms. Annals of Botany 96: 229-244. 